\title{
IGNACIO ARROYO MARTÍNEZ, ESTUDIOS DE DERECHO MARÍTIMO, BARCELONA, LIBRERÍA BOSCH, 1985, 654 PP.
}

\author{
Sergio Peña Neira (iD)
}

Los textos que se reúnen en el volumen editado por Bosch, hacen honor a su denominación "Estudios". Constituyen, además, una fuente interesante para investigaciones acabadas sobre lo jurídico marítimo, y orientarse desde el punto de vista dogmático jurídico en la evolución y los problemas que presenta el Derecho marítimo.

Para cualquiera que se inicia en lo marítimo internacional desde una perspectiva jurídica, compenetrarse del tema acompañado de una de sus principales figuras posee un valor significativo. Si además se posee el título de catedrático en la Universidad Autónoma de Barcelona, Doctor en Derecho por la afamada Universidad de Bolonia y Magister en Derecho por la Universidad de Harvard, podemos estar seguros que la calidad académica tiene fundamento. Unir a ello la calidad personal del doctor Arroyo, a quien conocimos en 1994, lleva a maravillarse en el aprendizaje del Derecho marítimo.

La temática abordada posee, digámoslo desde el comienzo, un hilo conductor, a saber, la noción de Derecho marítimo. No es ocioso determinar el sentido y alcance de tal concepto. Sucede, entonces, a una cátedra que entrega información, una disciplina que presenta un sistema. Precisamente el primero de los textos ofrecidos al lector se refiere a este tema, en un análisis pormenorizado de las diferentes tendencias que pueblan la dogmática (p.33) y, conjuntamente con una suerte de delimitación del objeto y de un desarrollo histórico, acercándose al Derecho comparado. En este último, los ordenamientos jurídicos estudiados son el Derecho inglés y norteamericano, con su perspectiva procesal llevada al denominado Derecho del Almirantazgo (p.42). la idea del particularismo en el Derecho francés ( $p .63)$ y el denominado Derecho de la Navegación, proveniente de la doctrina italiana (p.68).

Respecto del primero de los nombrados, el anglosajón, le critica el Dr. Arroyo la falta de un desarrollo científico del tema. Principalmente se toman en consideración en este sistema criterios de carácter material, en donde es involucrada una extensión o densidad de la materia más que una conceptualización o sistematicidad (p.42). Preside la sistemática jurídica anglosajona el empirismo en las soluciones, y la ausencia de pretensión generalizadora fuera de los estrechos límites del caso concreto, así como la adecuación de las necesidades reales en que se desintegra un conflicto de intereses, fórmulas todas, que caracterizan al ordenamiento proveniente del Common Law. Se tiene en consideración el que la creación judicial del Derecho, el precedente judicial vinculatorio y la relevancia del procedimiento, son notas caracteristicas de este ordenamiento (p.43). Existe en él una administración de justicia especial, exclusiva de lo marítimo, denominada Tribunal del Almirantazgo.

El segundo, el francés, actúa sobre la base del particularismo. Ello implica el que en el contexto histórico se establece como fuente del ordenamiento jurídico marítimo 
los usos y las costumbres, con una vulgarización del lenguaje, y ello hace la diferencia con el derecho tradicional de origen romano cuya base es el latín como lengua. Diferentes autores que abordan esta idea desde una concepción iusprivatista son estudiados en una amplia crítica (p.65).

En el Derecho italiano, por último, la nota distintiva, a su vez, es la noción de autonomía. Ello se refuerza a través de un código que aborda en todas sus partes (tanto pública como privada) el tema de lo marítimo. Además se incluye la idea de la especialidad. La autonomía implica por cierto, que el propio Derecho positivo revela una disciplina orgánica para una categoría particular de relaciones. En este ámbito, el Derecho marítimo se califica por su objeto, el transporte marítimo, y de allí el calificativo de Derecho de la Navegación (ps.69,70).

Luego el autor efectúa un análisis de los nuevos hechos que informan al Derecho marítimo (p.72), y un primer aspecto de ellos, la uniformidad internacional. Es de todos sabido que, luego de un arduo debate, no sólo doctrinario, se ha impuesto el consenso suficiente para poder establecer normas jurídicas reguladoras con ribetes de generalidad a nivel internacional. Tradicionalmente, o se establecían acuerdos entre paises. denominados tratados o se aceptaban ciertos textos jurídicos, que por su importancia o por haberse convertido en costumbre, pasaban a ser considerados como propios del ordenamiento jurídico. Lo anterior tiene su origen en la falta de un ordenamiento jurídico internacional, a la usanza de los criterios empleados por autores que se han ocupado del tema, como Kelsen. Del mismo modo se alcanzaba dicha uniformidad a través del uso constante de determinados documentos entre partes que, al nacer de la voluntad de las mismas, les daba la calidad de normas jurídicas. Es materia maritima la situación no es diferente. El Comité Marítimo Internacional, las Naciones Unidas a través de la UNCTAD y la UNCITRAL, y lo mismo la Cámara de Comercio Internacional, han propugnado la uniformidad de textos que vengan a satisfacer las necesidades de los actores jurídicos internacionales. Estos entes han ido estableciendo una serie de consensos relativos a diversas materias, como lo marítimo público o privado. Es decir, existen nuevos criterios en la producción de normas. Incluso, tras efectuar esta afirmación, el Dr. Arroyo argumenta en contra de una serie e instituciones que tienen como fundamento la protección de porteadores o navieros (p.77). Es la búsqueda de la protección de los usuarios, llevada adelante por UNCTAD, representada la desproporción por las denominadas conferencias marítimas. A su vez la base de los conceptos que tradicionalmente han mantenido su sentido (vgr. buque), sufren modificación dado el progreso de la tecnología ( $p .82$ ). Aerodeslizadores y plataformas de perforación vienen a generar esta nueva situación de incertidumbre, ya que la doctrina no logra efectuar un análisis que permita incorporar éstos y otros nuevos elementos o categorías utilizadas previa o preexistentes (p.83). Las legislaciones tienen igual dificultad en su clasificación y determinación ( $p .83$ ), incluso aplicando normativa proveniente de otros ámbitos, como el aéreo (p.83). Así también se incluye, dentro de estos nuevos conceptos, el Derecho del Mar, de 1982, con una serie de conferencias preparatorias a la misma (p.85). En ella existió una fuerte presencia de los países del Tercer Mundo frente a los industrializados en la gestión de los recursos provenientes del mar, así como de la exploración y explotación del mismo (p.92).

En las consideraciones finales a este tema, y tras de una breve recapitulación en donde efectúa un análisis a los diferentes argumentos tratados, concluye que el mar no se aviene a criterios de Derecho público y privado (p.96). Hace alcance, sin embargo, al 
tema de la publicización del Derecho marítimo (p.97), fenómeno que no es del todo extraño en Chile.

Es en este contexto, llegando más allá de posiciones en que subyacen conteniendo elementos públicos y privados, formula la definición de lo que el Derecho marítimo es: "el conjunto de relaciones jurídicas que nacen o se desarrollan con el mar" (p.98). No se trata, según advierte el mismo autor, de generar una yuxtaposición entre la internacionalización del Derecho marítimo privado con el fenómeno inverso: la privatización del derecho público (p.99). Lo que se pretende es aplicar los conceptos propios de la ciencia jurídica al mar y a las actividades que en él se desarrollan. Se pasa directamente a una ciencia del Derecho marítimo. Sustantiviza a la ciencia del Derecho aplicado al mar y adjetiviza lo marítimo (p.100).

El segundo de los artículos es una pormenorizada explicación acerca de los diferentes organismo que se encuentran relacionados con el tráfico marítimo. Clasifica a los mismos en organismos no vigentes y los vigentes. Pasa luego revisión a los organismos internacionales intergubernamentales y a las organizaciones internacionales no gubernamentales, así como los organismos nacionales (en este caso españoles). (Especial significación en este estudio tiene la Organización Marítima Internacional, UNCTAD a través de su comité de transporte marítimo, la Comisión de Naciones Unidas sobre el Derecho comercial internacional conocida como UNCITRAL, el Comité Marítimo Internacional, la Conferencia Marítima Internacional y del Báltico (BIMCO, en inglés)).

Un tercer estudio se centra en el tema de los derechos históricos de pesquerías frente al Derecho de la Comunidad Económica Europea y al Derecho del Mar. El problema se sitúa en el acceso a las pesquerías internacionales, y se centra en el grave problema que significa para pescadores españoles y franceses la imposibilidad de acceder a los mismos, o por el contrario, el acceso y extracción indiscriminada de pescado (p.212). En resumen, el derecho de pesquerías es un derecho a acceso libre de pescadores habituales a caladeros situados en aguas bajo el control de otros estados (p.226). Se concluye que los pescadores tienen derecho a ser indemnizados por el Estado, frente a las lesiones que puedan sufrir por parte de pescadores extranjeros, cuando el Estado haya firmado acuerdos en que autorice la extracción.

Un cuarto estudio se refiere a la distribución del riesgo en el Derecho marítimo (p.232). Lo que se pretende es analizar la normativa vigente en España, a fin de disminuir los costes del tráfico marítimo producto de la incidencia de la regulación jurídica vigente relativa al riesgo y el seguro en el transporte de mercancía. Se parte de la idea que los daños producidos en el buque y en las mercancías es una constante del comercio marítimo, y el avance de la técnica puede disminuirlos pero jamás suprimirlos. Se hace una referencia a los daños en materia marítima y su inherencia a la actividad, pese a las diversas fórmulas empleadas a fin de aminorarlas (p.232). Desde que el "daño se produce hasta que ese coste se integra en el precio de venta de la mercancía en destino, hay una serie de pasos intermedios a los que el Derecho no puede ser ajeno. $Y$ no lo es porque las normas jurídicas establecen quién ha de soportar las consecuencias patrimoniales del siniestro" (p.232). A ello se le denomina la distribución del riesgo en Derecho marítimo (p.232). Luego, analiza el postulado economicista del Derecho, en que se propone prevenir el daño o atribuirlo al sujeto, primaria y directamente perjudicado, minimizando el coste del daño. Por tanto, los costes del seguro y del ejercício de la acción subrogatoria vendrían reflejados en el precio que implica la transferencia 
(p.233). Este punto es rechazado por el Dr. Arroyo adscribiendo, más bien, a una propuesta de justicia. Busca distribuir las desventajas patrimoniales en atención a las causas que las motivaron y a la conducta de los sujetos obligados (p.233). La distribución del riesgo, sin embargo, no es el último tema a estudiar.

El quinto artículo de este texto estudia los convenios internacionales y el Derecho interno, centrándose en la limitación de responsabilidad por abordaje. Partiendo del tema de la responsabilidad por abordaje en el derecho español y sus diversas formas (abordaje unilateral, por culpa común, fortuito, dudoso), desarrolla el contenido de la obligación de indemnización. Luego analiza la responsabilidad del naviero en el Derecho interno español (pp.360 y ss.), llegando a una materia de suyo importante como es el ámbito de aplicación material de los convenios internacionales ante supuestos nacionales (pp. 365 y ss.). Por último, aparece el tema del alcance máximo de la responsabilidad derivada del abordaje según el Código de Comercio español (pp. 399).

La responsabilidad quincenal del constructor de buques o el absurdo de un razonamiento jurídico correcto, resulta el sexto estudio de este texto. No nos detendremos mayormente en él aunque se hace necesario destacar el análisis del tema, construcción de buques con suministro de materiales por el comitente. De acuerdo con la doctrina del Tribunal Supremo español, es un arrendamiento de obra (pp. 416-418).

Un tema que de suyo tiene un valor muy grande para el estudioso de esta materia es el relativo a la relación entre conocimiento de embarque y el fletamento. Ellos son dos de los contratos que en el Derecho marítimo comercial han merecido mayor atención, y no siempre con claridad, por parte de la doctrina. El séptimo estudio aborda este tema con pristinidad meridiana. Luego de analizar al fletamento y al contrato de transporte, se centra el autor en la cláusula de incorporación (pp. 430 y ss.). Después de lo anterior, efectúa un pormenorizado y cuidadoso análisis acerca de la relación entre pólizas de fletamento y conocimiento de embarque a la luz de los títulos de valores y su doctrina, para concluir con los supuestos concretos de la incorporación.

Para finalizar los estudios estrictamente doctrinarios, ataca el tema de la jurisdicción internacional y el transporte marítimo internacional, en relación a la aplicación de la sentencia arbitral extranjera. Ello a la luz de la ley de arbitraje española de 1953, hoy día derogada.

Dos temas aborda al finalizar el texto. Las reseñas y comentarios efectuados por el autor a jurisprudencia española entre 1979 y 1983, relativas al tema marítimo y las fuentes de conocimiento del Derecho marítimo español. Ambas están a la misma altura en cuanto a calidad doctrinaria que los textos a los cuales no hemos referido, y servirán de guía a quienes deseen estudiarlos.

No se sabe bien dónde empieza el estudio de lo marítimo en su encuentro con quien efectúa el mismo. Ignacio Arroyo, sin lugar a dudas, en este texto y en los estudios que efectúa, logra una simbiosis entre la investigación y la enseñanza, sólo comparable con la que tiene él con el Derecho marítimo. Sencillamente esperamos que además de esta obra, ya reeditada por Bosch en 1993, y de otras que la editorial catalana tiene en sus catálogos, nos obsequie pronto con un Derecho marítimo, maduro, reclamado por el mundo castellano. 